\title{
INVESTIGATIONS OF CARBON DIOXIDE ABSORPTION INTO AQUEOUS POTASSIUM CARBONATE SOLUTIONS CONTAINING PRIMARY AND SECONDARY ALKANOLAMINES
}

\author{
Grzegorz Bińczak $^{* 1}$, Władysław Moniuk ${ }^{2}$,Zofia Mordecka ${ }^{1}$, Cezary Możeński ${ }^{1}$ \\ ${ }^{1}$ Institute of New Chemical Syntheses, Tysiaclecia Panstwa Polskiego 13A, Pulawy 24-110, Poland \\ ${ }^{2}$ Warsaw University of Technology, Faculty of Chemical and Process Engineering, Waryńskiego 1, \\ 00-645 Warsaw, Poland
}

Dedicated to Prof. Ryszard Pohorecki on the occasion of his 80th birthday

In the paper the results of measurements of $\mathrm{CO}_{2}$ absorption rate in aqueous potassium carbonate solutions containing cyclohexylamine, diethanolamine, 2-methylaminoethanol and triethylenetetramine as activators have been presented. Enhnancement mass transfer factors as well as reaction rate constants have been determined. Results show that among the tested activators triethylenetetramine and 2-methyl-aminoethanol may be used (instead of diethanolamine) as new promotors in a modified BENFLIELD process.

Keywords: carbon dioxide absorption, alkanolamines, potassium carbonates, laminar jet

\section{INTRODUCTION}

The absorption of carbon dioxide from synthesis gases by water has been practiced for many years, but it is now being superseded by the use of more specific absorbents. Several solvents such as propylene carbonate, methanol, N-methyl-2-pyrrolidine have been investigated, but only diethylene glycol acetate have been employed on a commercial scale. The removal of carbon dioxide from gas mixtures by contacting gases with a liquid solution exemplifies a class of chemical reactions that is both of theoretical and practical importance. Chemically reactive solvents usually have higher capacity and higher mass transfer rates than those based solely on physical absorption.

Capital investments (mainly solvent cost and equipment cost) and energy requirements for solvent regeneration are the two most important factors to be considered in selecting an appropriate process.

The most widely used chemical solvents employed for removal of acid gases such as $\mathrm{CO}_{2}, \mathrm{H}_{2} \mathrm{~S}$ and COS are:

- aqueous solution of alkanolamines such as MEA, DEA TEA, MDEA and DIPA (Vaidya and Kenig, 2010),

- potassium carbonate solution with addition of alkanolamines.

The use of a promoted potassium carbonate solution at a temperature of ca. $100^{\circ} \mathrm{C}$ has the advantage over an aqueous solution of alkanolamines in terms of its lower cost and better suitability for regeneration purposes, because it requires less steam for stripping than the cold solvent. A hot 
carbonate process with DEA as an activator was originally developed by Benson et al. in late 1950s (BENFIELD process).

Several research groups have investigated new alkanolamines activators for $\mathrm{CO}_{2}$ absorption into potassium carbonate solutions (Bińczak et al., 2013; Cullinane and Rochelle, 2004; Kim et al., 2012; Pohorecki et al. 1988; Tseng et al., 1988; Yih and Sun, 1987).

The aim of this work was to evaluate the suitability of new alkanolamines activators (such as cyclohexylamine, 2-methylaminoethanol and triethylenetetramine) for synthesis gases purification in the modified BENFIELD process. The work is a part of a wider experimental program aimed at the development of a new activator in the process of $\mathrm{CO}_{2}$ absorption during ammonia synthesis.

\section{ABSORPTION MODEL}

The following reactions occur during the $\mathrm{CO}_{2}$ absorption into aqueous potassium carbonate solutions with alkanolamines used as activators

$$
\begin{gathered}
\mathrm{CO}_{2_{(\mathrm{g})}} \leftrightarrow \mathrm{CO}_{2_{(\mathrm{aq})}} \\
\mathrm{CO}_{2_{(\mathrm{aq})}}+\mathrm{H}_{2} \mathrm{O} \leftrightarrow \mathrm{H}^{+}+\mathrm{HCO}_{3}^{-} \\
\mathrm{H}_{2} \mathrm{O} \leftrightarrow \mathrm{H}^{+}+\mathrm{OH}^{-} \\
\mathrm{CO}_{2_{(\mathrm{aq})}}+\mathrm{OH}^{-} \leftrightarrow \mathrm{HCO}_{3}^{-} \\
\mathrm{HCO}_{3}^{-} \leftrightarrow \mathrm{H}^{+}+\mathrm{CO}_{3}^{2-} \\
2 \mathrm{RR}^{\prime} \mathrm{NH}+\mathrm{CO}_{2_{(\mathrm{aq})}} \leftrightarrow \mathrm{RR}^{\prime} \mathrm{NCOO}^{-}+\mathrm{RR}^{\prime} \mathrm{NH}_{2}^{+} \\
\mathrm{RR}^{\prime} \mathrm{NCOO}^{-}+\mathrm{H}_{2} \mathrm{O} \leftrightarrow \mathrm{RR}^{\prime} \mathrm{NH}+\mathrm{HCO}_{3}^{-} \\
\mathrm{RR}^{\prime} \mathrm{NH}_{2}^{+} \leftrightarrow \mathrm{RR}^{\prime} \mathrm{NH}+\mathrm{H}^{+}
\end{gathered}
$$

As can be seen, $\mathrm{CO}_{2 \text { aq }}$ reacts in three parallel reactions with $\mathrm{H}_{2} \mathrm{O}, \mathrm{OH}^{-}$ions and alkanolamines. The reaction with water is first-order, whereas reactions with $\mathrm{OH}^{-}$ions and alkanolamines are second-order. For the pseudo-first order chemical reaction (see adequate criterion in Appendix) the reaction rate constant $k_{1}$ can be expressed as in Eq. (9):

$$
k_{l}=k_{\mathrm{H}_{2} \mathrm{O}}+k_{\mathrm{OH}^{-}}\left[\mathrm{OH}^{-}\right]+k_{\mathrm{Am}}[\mathrm{Am}]
$$

The rate constant $k_{\mathrm{H}_{2} \mathrm{O}}$ for the reaction (2) does not depend on the ionic strength of the solution and may be calculated from Eq. (10) (Danckwerts and Sharma, 1966)

$$
\log k_{\mathrm{H}_{2} \mathrm{O}}=329.85-110.541 \log T-\frac{17265.4}{T}
$$

From equilibrium constants of the reaction (5)

$$
K_{2}=\frac{\left[\mathrm{H}^{+}\right]\left[\mathrm{CO}_{3}^{2-}\right]}{\left[\mathrm{HCO}_{3}^{-}\right]}
$$

and reaction (3)

$$
K_{w}=\left[\mathrm{OH}^{-}\right]\left[\mathrm{H}^{+}\right]
$$


we get:

$$
\left[\mathrm{OH}^{-}\right]=\frac{K_{w}}{K_{2}} \frac{\left[\mathrm{CO}_{3}^{2-}\right]}{\left[\mathrm{HCO}_{3}^{-}\right]}=\frac{K_{w}}{K_{2}}\left(\frac{1-\alpha}{2 \alpha}\right)
$$

where the carbonisation ratio $\alpha$ is defined as in Eq. (14):

$$
\alpha=\frac{\left[\mathrm{HCO}_{3}^{-}\right]}{2\left[\mathrm{CO}_{3}^{2-}\right]+\left[\mathrm{HCO}_{3}^{-}\right]}
$$

The product $k_{\mathrm{OH}^{-}}\left[\mathrm{OH}^{-}\right]$can be expressed as in Eq. (15):

$$
k_{\mathrm{OH}^{-}}\left[\mathrm{OH}^{-}\right]=k_{\mathrm{OH}^{-}} \frac{\mathrm{K}_{\mathrm{w}}}{K_{2}} \frac{1-\alpha}{2 \alpha}=K_{R} \frac{1-\alpha}{2 \alpha}
$$

where the kinetic coefficient $K_{R}$ is expressed by the Eq. (16):

$$
K_{R}=k_{\mathrm{OH}^{-}} \frac{K_{w}}{K_{2}}
$$

and can be calculated from the following relation (Pohorecki and Kucharski, 1991)

$$
\ln K_{R}=27.821-\frac{8514}{T}+0.5456 I-0.0276 I^{2}
$$

\section{EXPERIMENTS AND METHOD OF CALCULATIONS}

The measurements of the $\mathrm{CO}_{2}$ absorption rate were carried out at a normal pressure using a laminar jet absorber. The experimental apparatus is shown in Fig.1. A detailed description of the apparatus and the measuring technique can be found elsewhere (Pohorecki, 1972; Bińczak et al., 2013).

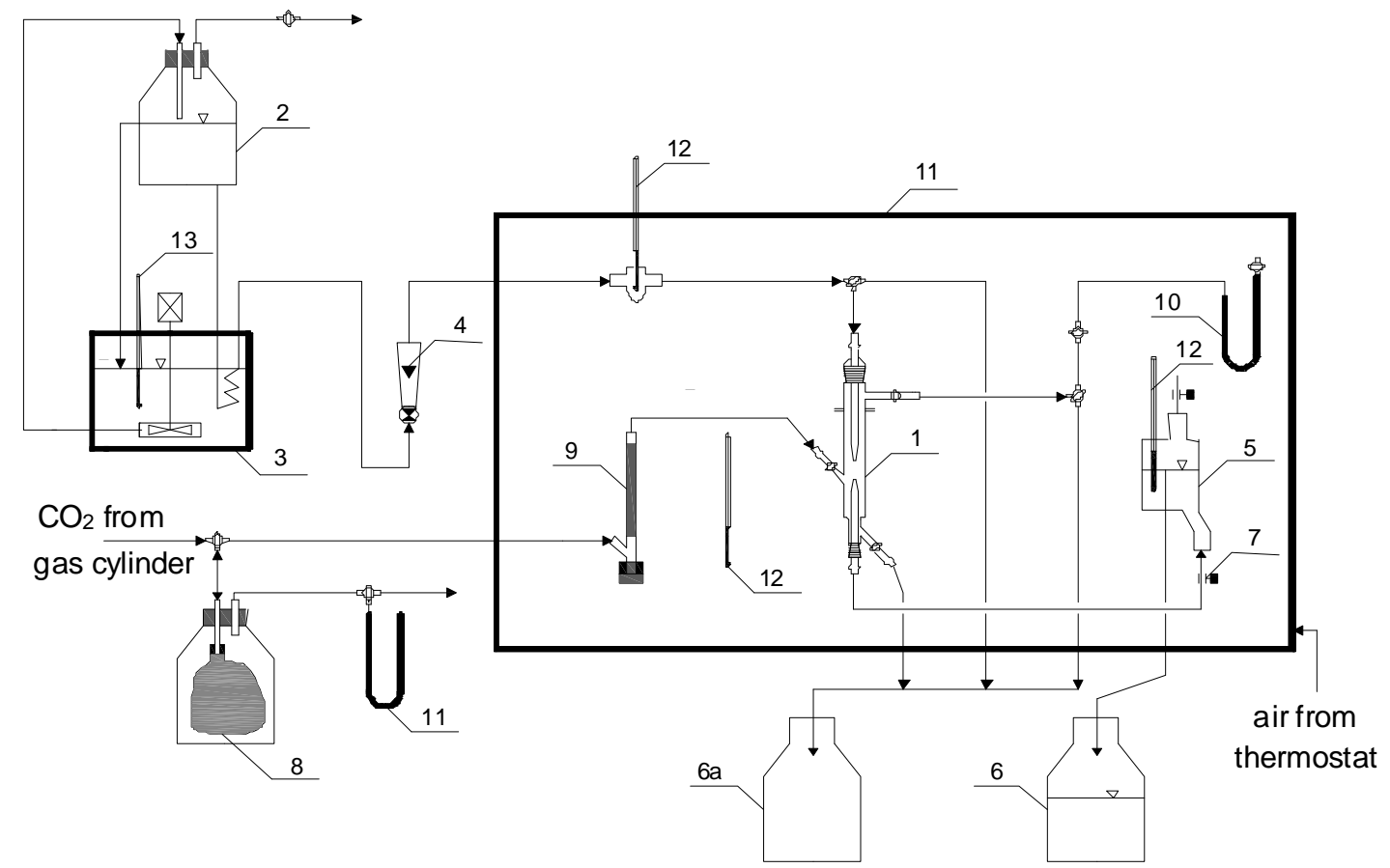

Fig. 1. Scheme of the experimental apparatus. 1- laminar jet absorber, 2- liquid tank, 3- thermostat, 4- rotameter, 5- overflow, 6- receiving tank, 7- clamp, 8- balloon with $\mathrm{CO}_{2}$, 9- soap-film meter, 10- manometer, 11- perspex chamber, 12, 13- thermometers 
The measurements were carried out in the temperature range of $20-40{ }^{\circ} \mathrm{C}$ at atmospheric pressure. Total concentration of carbonates (expressed as equivalent weight fraction of $\mathrm{K}_{2} \mathrm{CO}_{3}$ ) was $8 \mathrm{wt} \%$, with carbonisation ratio of 0.4 . The following activators were used: cyclohexylamine (CHA) $3 \mathrm{wt} \%$; diethanolamine (DEA) 1-3 wt\%; 2-methylaminoethanol (2-MAE) 1-3 wt\% end triethylenetetramine (TETA) $1-3 \mathrm{wt} \%$. CHA is a primary amine; DEA and 2-MAE are secondary amines; TETA has got two groups of primary amines $\left(-\mathrm{NH}_{2}\right)$ and two groups of secondary amines (-NH-).

In the absorption process with a reversible chemical reaction, the molar flux $N_{A}$ of the absorbed component is expressed as:

$$
N_{A}=k_{L}^{*}\left(C_{A i}-C_{A r}\right)
$$

and the absorption rate $R$ is:

$$
R=N_{A} a=k_{L}^{*}\left(C_{A i}-C_{A r}\right) a
$$

For the laminar jet absorber the interfacial area $a$ may be assumed according to Eq. (20):

$$
a=\pi d l
$$

The measured absorption rate $R$ is:

$$
R=\frac{V_{g} p_{\mathrm{CO}_{2}}}{\bar{R} T}
$$

The concentration of $\mathrm{CO}_{2}$ at the interface can be calculated from the Henry's law:

$$
C_{A i}=H p_{A i}
$$

In the experiments, pure $\mathrm{CO}_{2}$ (saturated only with water vapour) was used.

$$
p_{A i}=p_{A 0}=P-p_{\mathrm{H}_{2} \mathrm{O}}
$$

The Henry's constant for $\mathrm{CO}_{2}$-aqueous potassium carbonate solutions can be calculated from the following relations (Barrett, 1966; Danckwerts, 1970):

$$
\begin{gathered}
\log \frac{H}{H_{w}}=-\sum I_{i} h_{i} \\
h_{i}=h_{+}+h_{-}+h_{g} \\
\log H_{w}=9.1229-5.9044 \times 10^{-2} T+7.8857 \times 10^{-5} T^{2}
\end{gathered}
$$

From equilibrium constants of the reactions (5), $K_{2}$ and (2), $K_{1}$

$$
K_{1}=\frac{\left[\mathrm{H}^{+}\right]\left[\mathrm{HCO}_{3}^{-}\right]}{\left[\mathrm{CO}_{2}\right]}
$$

we have

$$
\left[\mathrm{CO}_{2}\right]=C_{A r}=\frac{K_{2}}{K_{1}} \frac{\left[\mathrm{HCO}_{3}^{-}\right]^{2}}{\left[\mathrm{CO}_{3}^{2-}\right]}
$$

Making use of Eq. (14), we obtain:

$$
C_{A r}=\frac{4 \alpha^{2}}{1-\alpha} \frac{K_{2}}{K_{1}}\left\{\left[\mathrm{CO}_{3}^{2-}\right]+\frac{1}{2}\left[\mathrm{HCO}_{3}^{-}\right]\right\}
$$

The equilibrium partial pressure of $\mathrm{CO}_{2}$ is equal to: 


$$
p_{A r}=\frac{C_{A r}}{H}=\frac{4 \alpha^{2}}{1-\propto} \frac{K_{2}}{K_{1} H}\left\{\left[\mathrm{CO}_{3}^{2-}\right]+\frac{1}{2}\left[\mathrm{HCO}_{3}^{-}\right]\right\}=\frac{1}{K_{p}} \frac{4 \alpha^{2}}{1-\alpha}\left\{\left[\mathrm{CO}_{3}^{2-}\right]+\frac{1}{2}\left[\mathrm{HCO}_{3}^{-}\right]\right\}
$$

where the equilibrium coefficient $K_{p}$ is defined as:

$$
K_{p}=\frac{K_{1} H}{K_{2}}
$$

and can be calculated from the following relation (Pohorecki and Kucharski, 1991)

$$
\ln K_{p}=-3.154+\frac{2311}{T}-0.068 I+0.0138 I^{2}
$$

Making use of the experimental values of the absorption rate $R$ in Eq. (21), the values of the mass transfer coefficient with chemical reaction, $k_{L}^{*}$ were calculated from Eq. (19).

For fast, pseudo-first order chemical reactions, the mass transfer coefficient with a chemical reaction is equal to (see relevant criteria in the Appendix):

$$
k_{L}^{*}=\sqrt{D_{A} k_{1}}
$$

The diffusivity of $\mathrm{CO}_{2}$ in aqueous potassium carbonate solutions was calculated from the following relations (Barrett, 1966)

$$
\begin{gathered}
\left(D_{A} \mu\right)_{T}=\left(D_{w} \mu_{w}\right)_{T} \\
\log D_{w}=-8.1764+\frac{712.5}{T}-\frac{2.591 \times 10^{5}}{T^{2}}
\end{gathered}
$$

The viscosity of the solution was calculated using the relation proposed by Moniuk and Pohorecki (Moniuk and Pohorecki, 1991):

$$
\log \mu=\frac{844.279}{T}-2.8653+0.1458 S+0.0243 \alpha
$$

where:

$$
\log \mu=\frac{844.279}{T}-2.8653+0.1458 S+0.0243 \alpha
$$

The values of pseudo-first order reaction rate constant $k_{1}$ were calculated from Eq. (33) and values of second-order reaction rate $k_{A m}$ were calculated from Eq. (9).

\section{RESULTS AND DISCUSSION}

The determined values of mass transfer with a chemical reaction, $k_{L}^{*}$ were used for the calculation of the enhancement factor, $E$ using the following relation:

$$
E=\frac{k_{L}^{*}}{k_{L}}
$$

For the laminar-jet absorber, the physical mass transfer coefficient in the liquid phase may be calculated from the relation below (Higbie model)

$$
k_{L}=2 \sqrt{\frac{D_{A}}{\pi \tau}}
$$

where the contact time $\tau$ is given as:

$$
\tau=\frac{1}{u}=\frac{\pi d^{2} l}{4 V_{L}}
$$


In Fig. 2 the values of the enhancement factor, $E$, for the activators at $40^{\circ} \mathrm{C}$ are presented. As can be seen, the value of $E$ for CHA as an activator is lower than that for DEA. However, the values of $E$ for TETA and 2-MAE as activators are significantly higher than those for DEA.

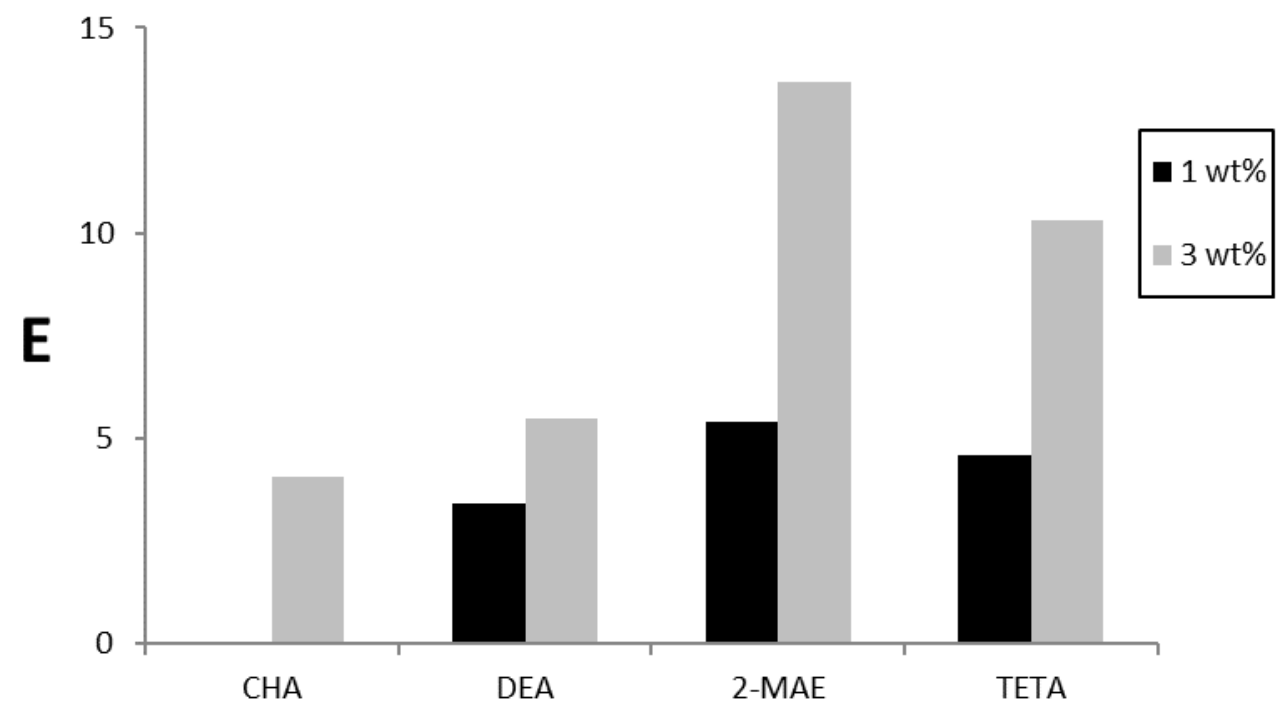

Fig. 2. The enhancement factor for the investigated activators

In Fig. 3 in Arrhenius plot $\left(\ln k_{A m}=\mathrm{f}\left(\frac{1}{T}\right)\right)$ for $\mathrm{CO}_{2}-\mathrm{CHA}$ system is presented. The straight line can be described by the relation:

$$
\ln k_{A m}=20.439-\frac{3681.6}{T}
$$

Due to the low activation properties of CHA we present only results for its highest investigated concentration.

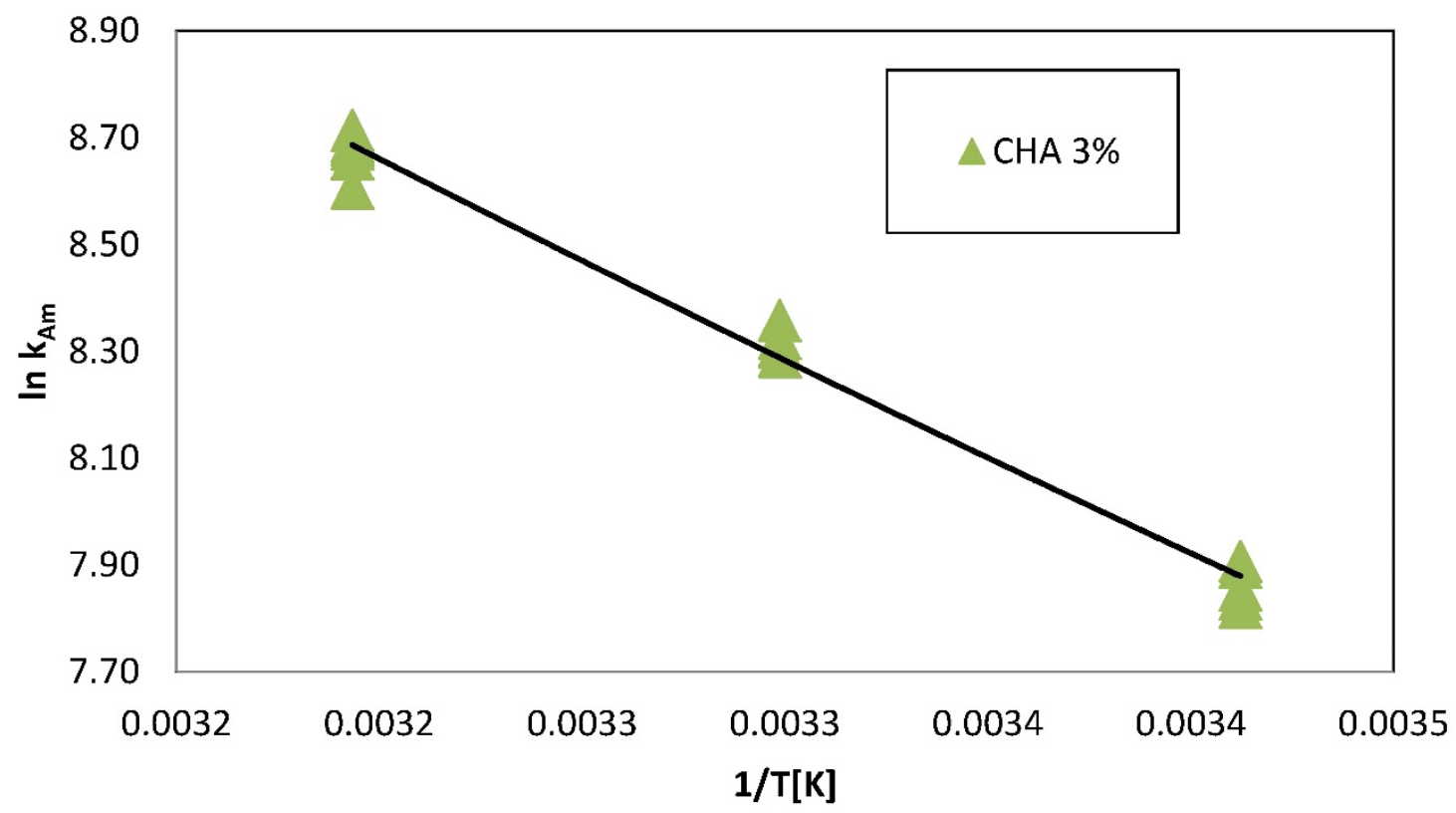

Fig. 3. Arrhenius plot $\left(\ln k_{A m}=\mathrm{f}\left(\frac{1}{T}\right)\right)$ for the $\mathrm{CO}_{2}-\mathrm{CHA}$ system 
In the literature there are no data on the kinetics of the reaction between $\mathrm{CO}_{2}$ and $\mathrm{CHA}$. It has been only mentioned (Cwalina and Kubicki, 1977) that CHA may be used as an activator in $\mathrm{CO}_{2}$ absorption into aqueous potassium carbonate solutions.

In Fig. 4 Arrhenius plots $\left(\ln k_{1}=\mathrm{f}\left(\frac{1}{T}\right)\right)$ for the $\mathrm{CO}_{2}-$ DEA system for different values of activator concentrations (1-3 wt\%) are presented. The results reveal that the values of the pseudo-first order reaction rate constants, $k_{1}$ significantly depend on the activator concentrations.

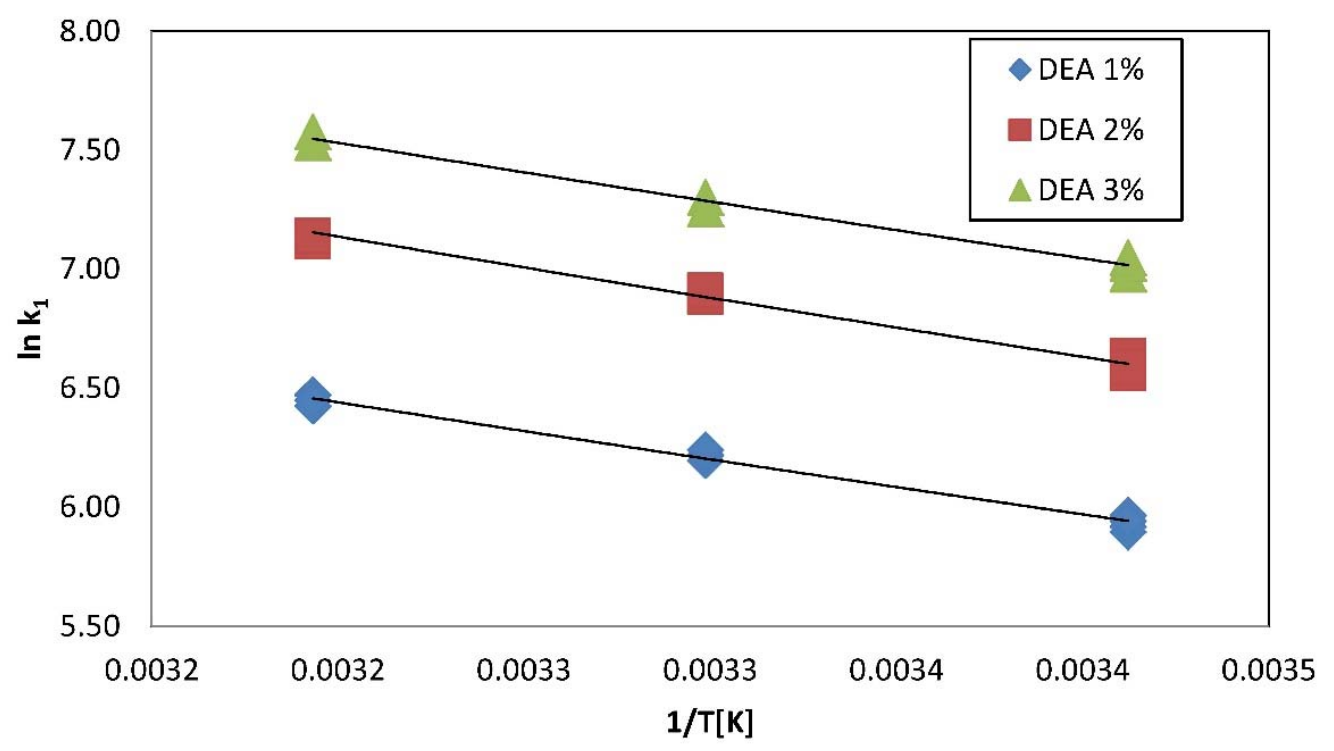

Fig. 4. Arrhenius plot $\left(\ln k_{1}=\mathrm{f}\left(\frac{1}{T}\right)\right)$ for the $\mathrm{CO}_{2}-$ DEA system

In Fig. 5 an Arrhenius plot $\left(\ln k_{A m}=\mathrm{f}\left(\frac{1}{T}\right)\right)$ for the $\mathrm{CO}_{2}-$ DEA system is presented. The data show that the values of the reaction rate constant, $k_{A m}$ practically do not depend on the activator concentrations. The straight line can be described by the following relation (42).

$$
\ln k_{A m}=7.1431-\frac{1048.9}{T}
$$

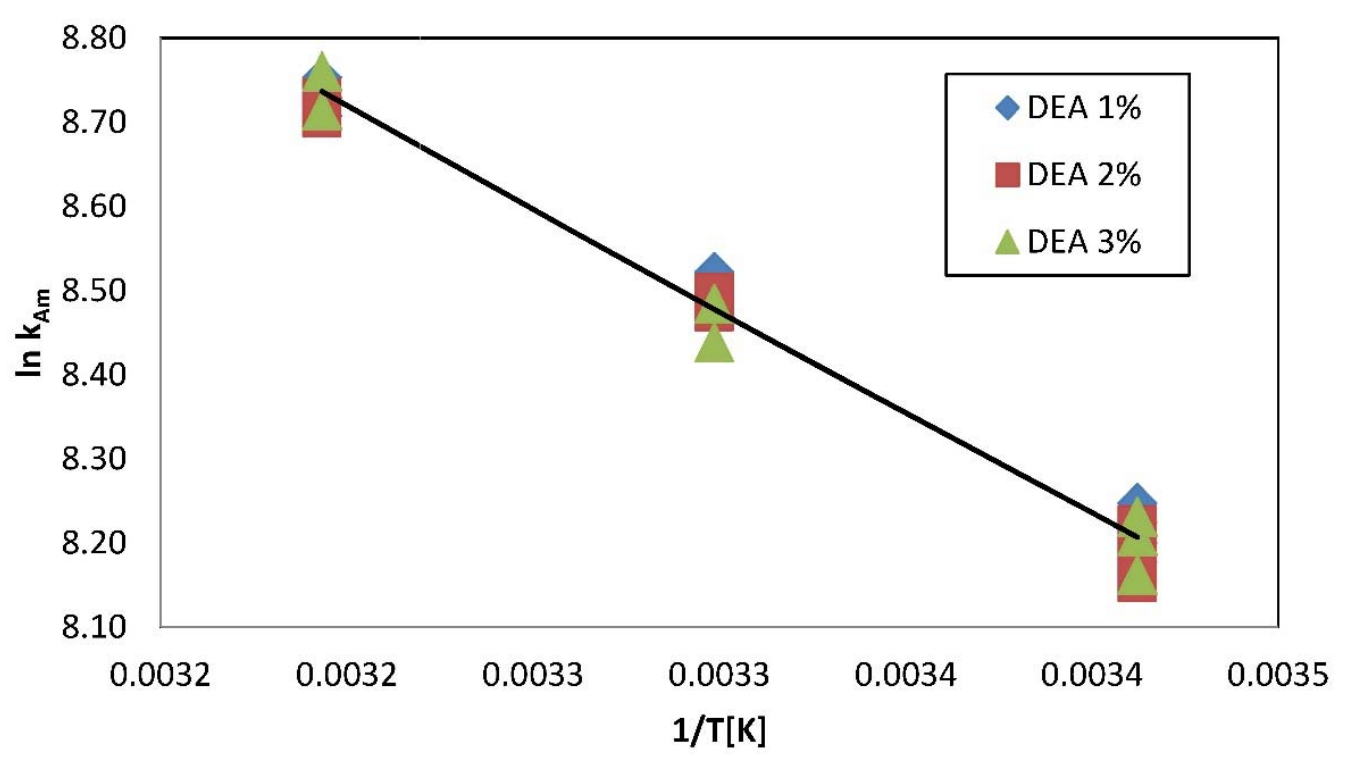

Fig. 5. Arrhenius plot $\left(\ln k_{A m}=\mathrm{f}\left(\frac{1}{T}\right)\right)$ for the $\mathrm{CO}_{2}-$ DEA system 
Table 1. Literature data on the kinetics for the reaction between $\mathrm{CO}_{2}$ and aqueous DEA

\begin{tabular}{|l|c|c|c|}
\hline \multicolumn{4}{|c|}{$\mathrm{CO}_{2}$-DEA (aqueous solutions) } \\
\hline \multicolumn{1}{|c|}{ Author } & $T, \mathrm{~K}$ & $\begin{array}{c}\text { DEA, } \\
\mathrm{kmol} / \mathrm{m}^{3}\end{array}$ & $\begin{array}{c}k_{\text {DEA }} \\
\mathrm{m}^{3} /(\mathrm{kmol} \cdot \mathrm{s})\end{array}$ \\
\hline Sharma, 1964 & 298 & 1 & 1240 \\
\hline Sada et al., 1976 & 298 & $0-1.922$ & 1340 \\
\hline Donaldson and Nguyen, 1980 & 298 & $0-0.88$ & 1400 \\
\hline Blanc and Demarais, 1981 & 298 & $0-4$ & 655 \\
\hline Barth et al., 1983 & 298 & 0.021 & 110 \\
\hline Laddha and Danckwerts, 1981 & 298 & $0-2.88$ & 1410 \\
\hline Blauwhoff et al., 1983 & 298 & $0-2.38$ & 7300 \\
\hline Versteeg and Oyevaar, 1989 & 298 & $0-4.358$ & 3240 \\
\hline Jensen et al., 1954 & 291 & $0-0.3$ & 5900 \\
\hline
\end{tabular}

DEA as an activator is commonly used in a number of industrial plants (BENFIELD process) and many studies have been performed on the kinetics of the reaction between $\mathrm{CO}_{2}$ and DEA. As it becomes evident from Table 1, discrepancies between results obtained by various authors (at $298 \mathrm{~K}$ ) are very large $\left(110-7300 \mathrm{~m}^{3} /(\mathrm{kmol} \cdot \mathrm{s})\right.$. At this temperature $k_{\mathrm{Am}}$ determined from the relation (42) amounts to $4200 \mathrm{~m}^{3} /(\mathrm{kmol} \cdot \mathrm{s})$.

In Fig. 6 Arrhenius plots $\left(\ln k_{1}=\mathrm{f}\left(\frac{1}{T}\right)\right)$ for the $\mathrm{CO}_{2}-2$-MAE system for a different values of activator concentrations (1-3 wt\%) are presented. The results reveal that the values of the pseudo-first order reaction rate constants, $k_{1}$ significantly depend on the activator concentrations.

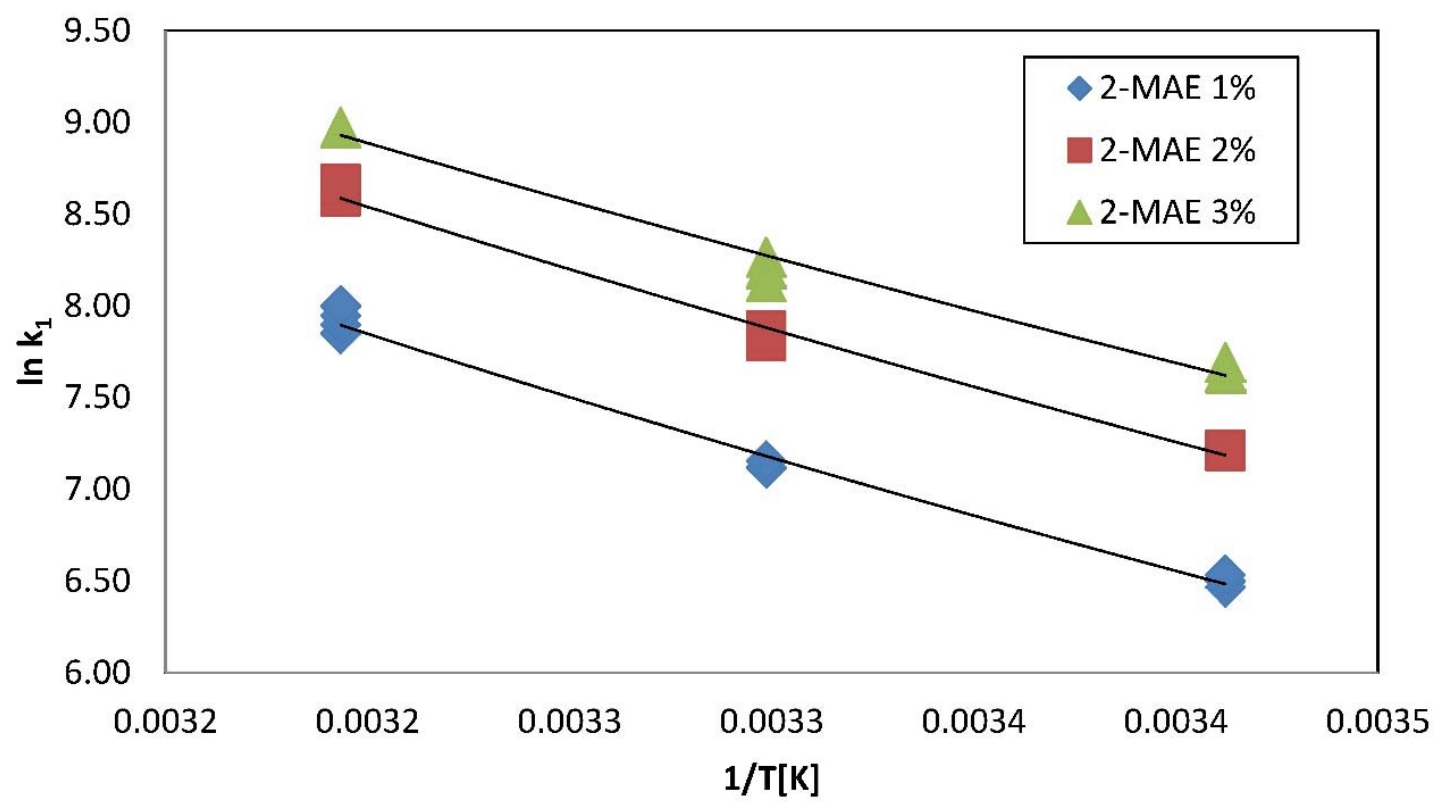

Fig. 6. Arrhenius plot $\left(\ln k_{1}=\mathrm{f}\left(\frac{1}{T}\right)\right)$ for the $\mathrm{CO}_{2}-2-\mathrm{MAE}$ system

In Fig. 7 an Arrhenius plot $\left(\ln k_{A m}=\mathrm{f}\left(\frac{1}{T}\right)\right)$ for the $\mathrm{CO}_{2}-2$-MAE system is presented. The data show that the values of the reaction rate constant, $k_{\mathrm{Am}}$ practically are independent of the activator concentration. The straight line can be described by the following relation (43). 


$$
\ln k_{A m}=29.925-\frac{6295.6}{T}
$$

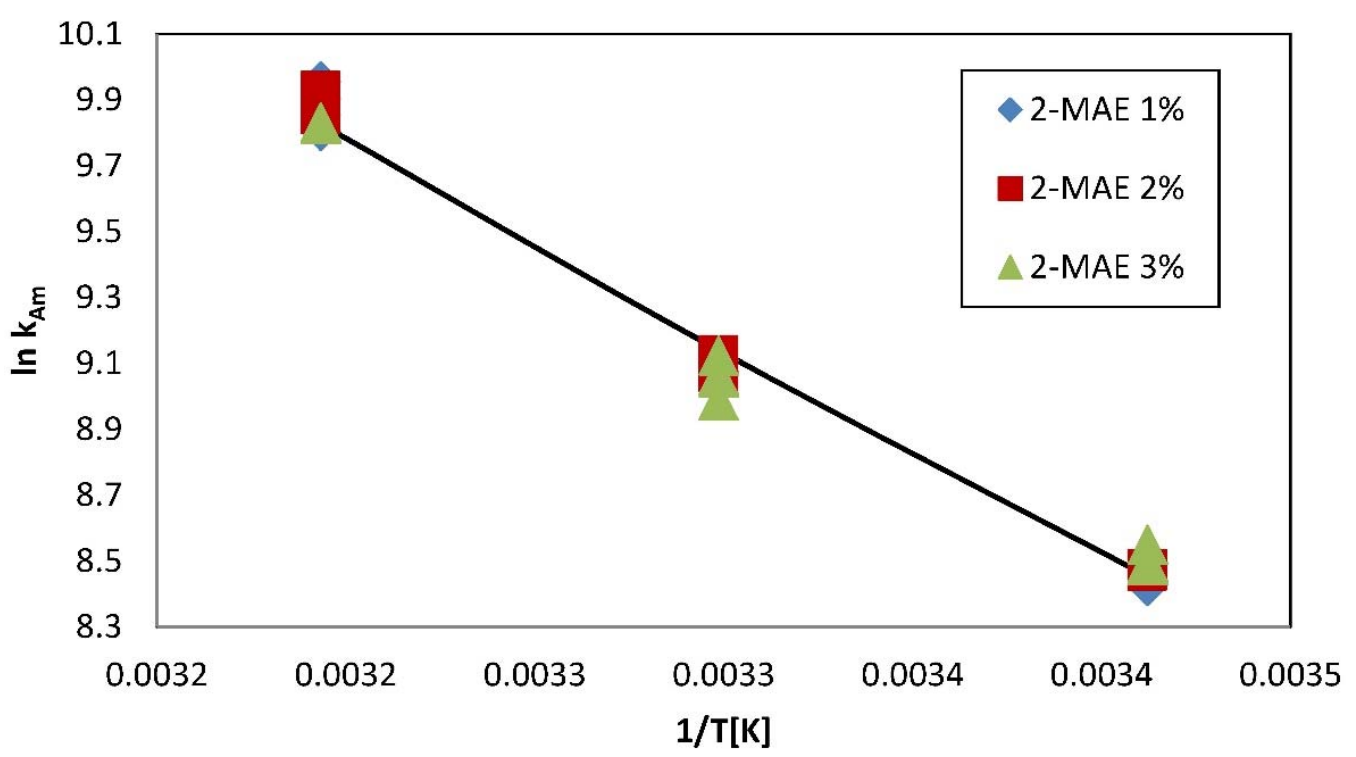

Fig. 7. Arrhenius plot $\left(\ln k_{A m}=\mathrm{f}\left(\frac{1}{T}\right)\right)$ for the $\mathrm{CO}_{2}-2-\mathrm{MAE}$ system

Mimura et al. (1988) investigated the kinetics of the reaction between $\mathrm{CO}_{2}$ and 2-MAE in aqueous solutions of 2-MAE $\left(0.9-2.5 \mathrm{kmol} / \mathrm{m}^{3}\right)$. At $298 \mathrm{~K}$, the value of the reaction rate constant, $k_{A m}$ amounts to $7940 \mathrm{~m}^{3} /(\mathrm{kmol} \cdot \mathrm{s})$. From Eq. (43) $k_{A m}$ is $6604 \mathrm{~m}^{3} /(\mathrm{kmol} \cdot \mathrm{s})$.

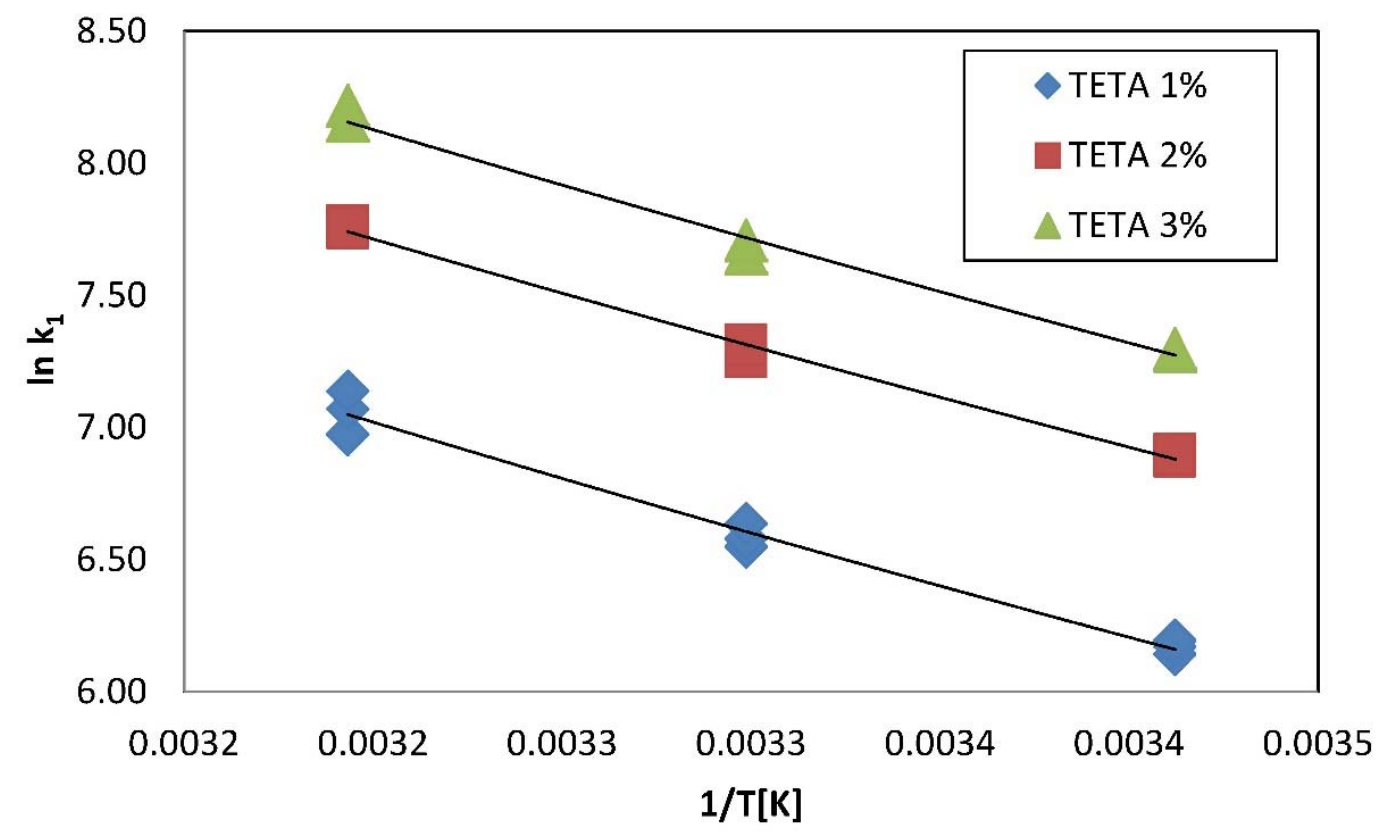

Fig. 8. Arrhenius plot $\left(\ln k_{1}=\mathrm{f}\left(\frac{1}{T}\right)\right)$ for the $\mathrm{CO}_{2}-$ TETA system

In Fig. 8 Arrhenius plots $\left(\ln k_{1}=\mathrm{f}\left(\frac{1}{T}\right)\right)$ for the $\mathrm{CO}_{2}$-TETA system for different values of the activator concentrations (1-3 wt\%) are presented. The results reveal that the values of the pseudo-first order reaction rate constants, $k_{1}$ significantly depend on the activator concentrations. 
In Fig. 9 an Arrhenius plot $\left(\ln k_{A m}=\mathrm{f}\left(\frac{1}{T}\right)\right)$ for the $\mathrm{CO}_{2}-$ TETA system is presented. As can be seen, the values of the reaction rate constant, $k_{A m}$ are practically independent of the activator concentrations. The straight line can be described by the following relation (44):

$$
\ln k_{A m}=22.500-\frac{4017.5}{T}
$$

Singh et al. (2009) investigated relationships between the structure the number of amine groups) and the activity of amine-based $\mathrm{CO}_{2}$ absorbents.

For the $\mathrm{CO}_{2}$-TETA system the total capacity of aqueous solutions is high and amounts to $2.51 \mathrm{~mol}$ $\mathrm{CO}_{2} / \mathrm{mol}$ amine or $17.15 \mathrm{~mol} \mathrm{CO}_{2} / \mathrm{kg}$ amine (Singh et al., 2009).

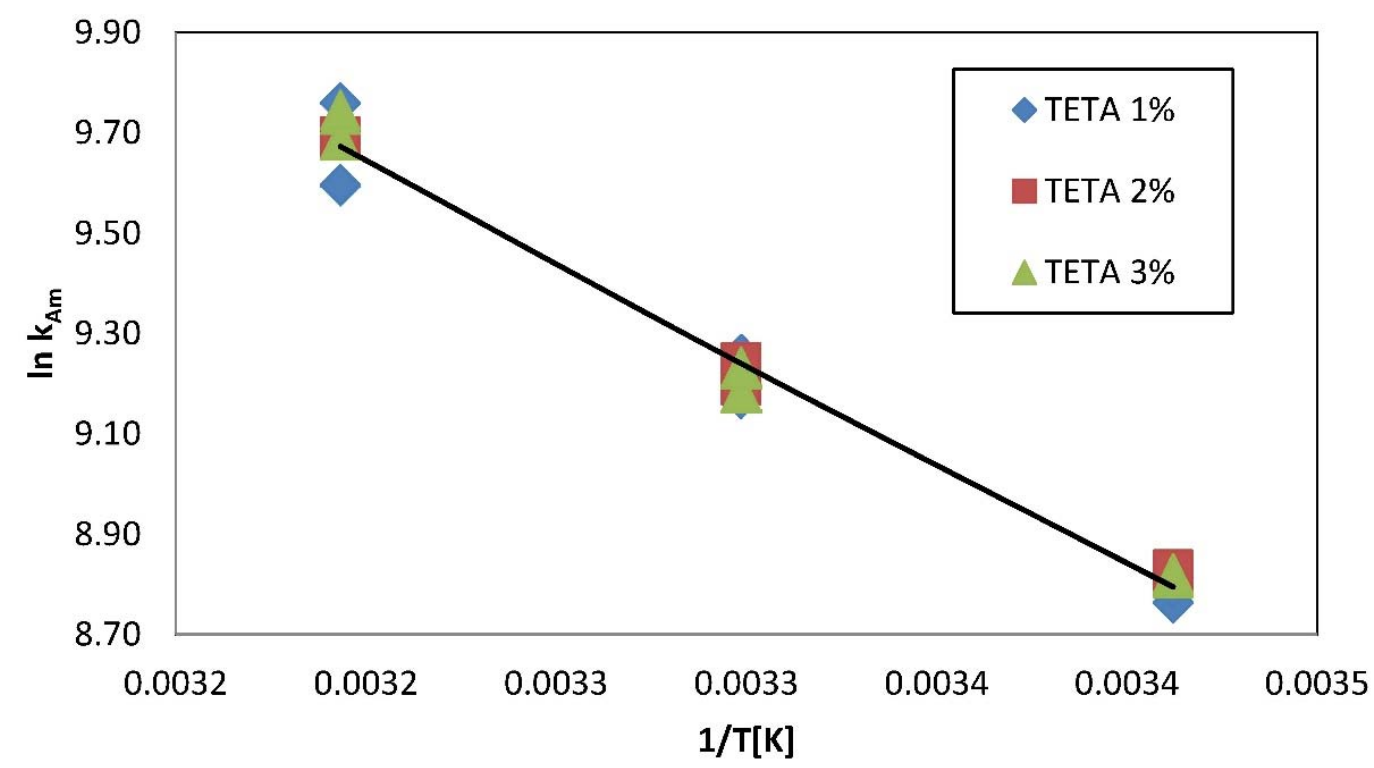

Fig. 9. Arrhenius plot $\left(\ln k_{A m}=\mathrm{f}\left(\frac{1}{T}\right)\right)$ for the $\mathrm{CO}_{2}-$ TETA system

\section{CONCLUSIONS}

Measurements of a $\mathrm{CO}_{2}$ absorption rate were carried out in aqueous potassium carbonate solutions containing alkanolamines (cyclohexylamine, diethanoloamine, 2-ethyl-aminoethanol and triethylenetetramine) using the laminar-jet technique. Enhancement mass transfer factors as well as reaction rate constants between $\mathrm{CO}_{2}$ and alkanolamines were determined. Results clearly show that triethylenetetramine and 2-methyl-aminoethanol may be used (instead of diethanolamine) as new activators of aqueous potassium carbonate/bicarbonate solution in a modified BENFLIELD process.

\section{SYMBOLS}

$\begin{array}{ll}a & \text { interfacial area, } \mathrm{m}^{2} \\ a & \text { concentration of carbonate ion Eq. (A2), } \mathrm{kmol} / \mathrm{m}^{3} \\ b & \text { concentration of bicarbonate ion Eq. (A2), } \mathrm{kmol} / \mathrm{m}^{3} \\ C_{A} & \text { molar concentration of component A, } \mathrm{kmol} / \mathrm{m}^{3} \\ D_{A} & \text { diffusivity of the absorbed gas in the liquid phase, } \mathrm{m}^{2} / \mathrm{s} \\ d & \text { nozzle diameter, } \mathrm{m} \\ E & \text { enhancement factor }\end{array}$




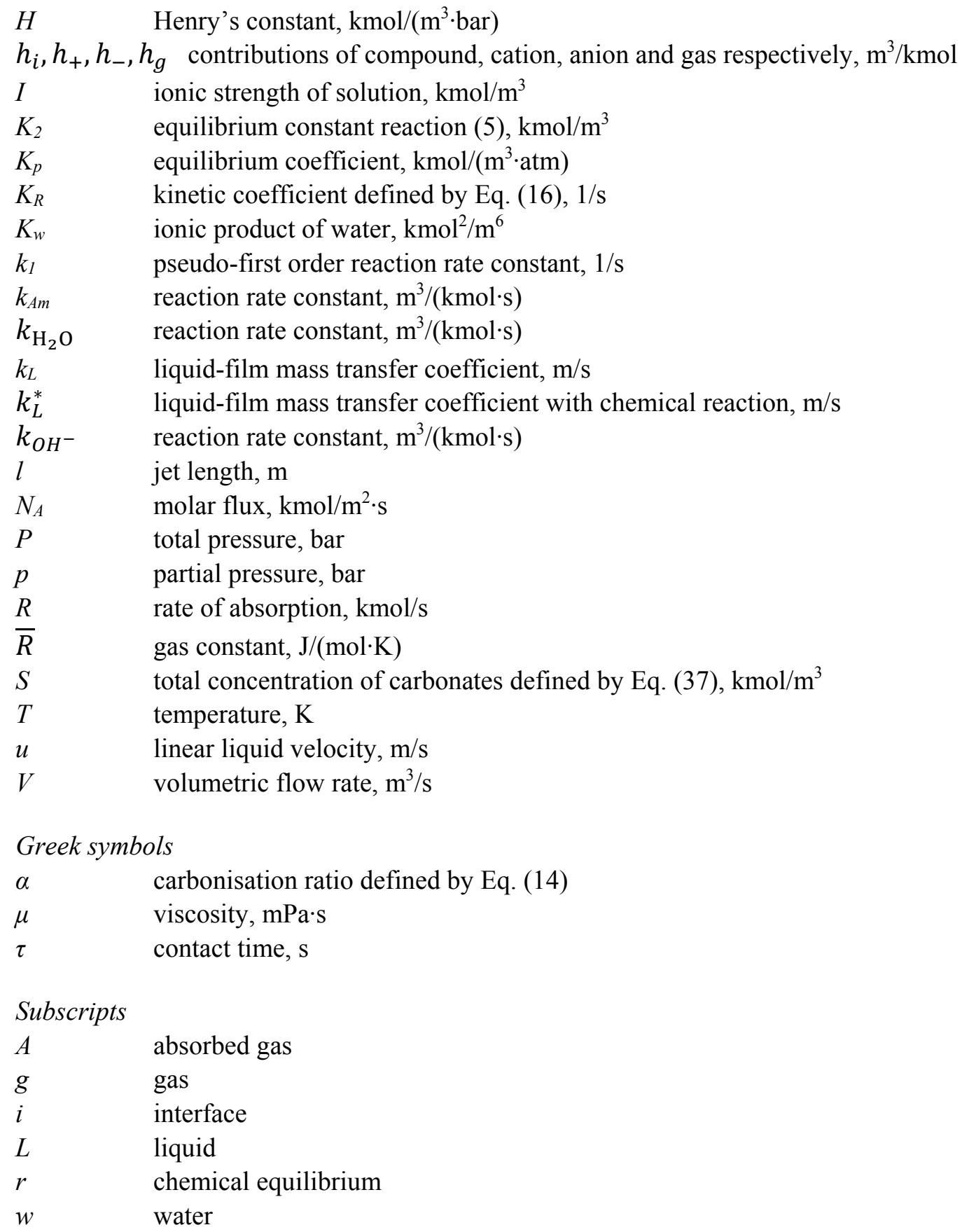

\section{REFERENCES}

Barrett P.V.L., 1966. Gas absorption on sieve plate. Ph. D. Thesis, University of Cambridge, Cambridge, 4-53.

Barth D., Tondre C., Delpuech J-J., 1983. Stopped-flow determination of carbon dioxide diethanolamine reaction mechanism. Kinetics of carbamate formation. Int. J. Chem. Kin., 15, 1147-1160. DOI: 10.1002/kin.550151104.

Benson H.E., Field J.H., Haynes W.P., 1956. Improved process for $\mathrm{CO}_{2}$ absorption used hot carbonate solutions. Chem. Eng. Prog., 52, 433-438.

Benson H.E., Field J.H., 1959. US Patent 2886405.

Bińczak, G., Pohorecki R., Moniuk W., Możeński C., Cwalina J., Mordecka Z., 2013. Study of carbon dioxide absorption in aqueous solutions of potassium carbonate activated with alkanolamines. Przem. Chem., 92, 321324 (in Polish).

Blanc C., Demarais G., 1981. Vitesses de la réaction du $\mathrm{CO}_{2}$ avec la diéthanolamine. Entropie, 102, 53-61.

Blauwhoff P.M.M., Versteeg G.F., van Swaaij W.P.M., 1983. A study on the reaction between $\mathrm{CO}_{2}$ and alkanolamines in aqueous solutions. Chem. Eng. Sci., 38, 1411-1429. DOI: 10.1016/0009-2509(83)80077-3. 
Cullinane J.T., Rochelle G.T., 2004. Carbon dioxide absorption with aqueous potassium carbonate promoted by piperazine. Chem. Eng. Sci., 59, 3619-3630. DOI: 10.1016/j.ces.2004.03.029.

Cwalina J., Kubicki J., 1977. Effect of selected activators on carbon dioxide absorption in potassium carbonates solution. Chemia Stosowana (Applied Chemistry), 11, $47-57$ (in Polish).

Danckwerts P.V., Sharma M.M., 1966. The absorption of carbon dioxide into solutions of alkalis and amines (with some notes on hydrogen sulphide and carbonyl sulphide). I. Chem. E. Review Series, No 2, The chemical Engineer, CE 244-278.

Danckwerts P.V., 1970. Gas-liquid reactions. McGraw-Hill Book Company, New York, 17-21.

Donaldson T.L., Nguyen Y.N., 1980. Carbon dioxide reaction kinetics and transport in aqueous amine membranes. Ind. Eng. Chem. Fundam., 19, 260-266. DOI: 10.1021/i160075a005.

Jensen M.B., Jorgensen B., Faurholt C., 1954. Reactions between carbon dioxide and aminoalcohols. I. Monoethanoloamine and diethanolamine. Acta Chem. Scand., 8, 1137-1140. DOI: 10.3891/acta.chem.scand.081137.

Kim Y.E., Choi J.H., Nam, S.C., Yoon Y.L., 2012. $\mathrm{CO}_{2}$ absorption capacity using aqueous potassium carbonate with 2-methylpiperidine and piperazine. J. Ind. Eng. Chem., 18, 105-110. DOI: 10.1016/j.jiec.2011.11.078.

Laddha S.S., Danckwerts P.V., 1981. Reaction of $\mathrm{CO}_{2}$ with ethanolamines: Kinetics from gas absorption. Chem. Eng. Sci., 36, 479-482. DOI: 10.1016/0009-2509(81)80135-2.

Leder F., 1971. The absorption of $\mathrm{CO}_{2}$ into chemically reactive solutions at high temperatures. Chem. Eng. Sci., 26, 1381-1390. DOI: 10.1016/0009-2509(71)80058-1.

Mimura T., Suda T., Iwacki I., Honda A., Kumazawa H., 1998. Kinetics of reaction between carbon dioxide and sterically hindered amines for carbon dioxide recovery from power plant flue gases. Chem. Eng. Comm., 170, 245-260. DOI: 10.1080/00986449808912745.

Moniuk W., Pohorecki R., 1991. Viscosity and density of sodium and potassium alkaline solutions. Hung. J. Ind. Chem., 19, 175-178.

Pohorecki R., Wroński S., 1977. Kinetics and thermodynamics of chemical engineering processes. WNT, Warsaw, 482-486 (in Polish).

Pohorecki R., 1972. Measurements of reaction rate constant for absorption of $\mathrm{CO}_{2}$ into $\mathrm{K}_{2} \mathrm{CO}_{3} / \mathrm{KHCO}_{3}$ solutions containing $\mathrm{KCl}$ and $\mathrm{NaOCl}$. Inż. Chem. 2, 383-402 (in Polish).

Pohorecki R., Xoan D.T., Moniuk W., 1988. Study of carbon dioxide absorption in aqueous solution of potassium carbonate containing ethylaminoethanols. II. Kinetic relations for 2-ethylaminoethanol. Inż. Chem. Proc., 9, 667-680 (in Polish).

Pohorecki R., Kucharski E., 1991. Desoprtion with chemical reaction in the system $\mathrm{CO}_{2}$-aqueous solution of potassium carbonate. Chem. Eng. J., 46, 1-7.

Sada E., Kumazawa H., Butt M.A., 1976. Gas absorption with consecutive chemical reaction: Absorption of carbon dioxide into aqueous amine solutions. Can. J. Chem. Eng., 31, 421-424. DOI: 10.1002/cjce.5450540507.

Sharma M.M., 1964. Kinetics of gas absorption. Ph. D. Thesis, University of Cambridge, Cambridge.

Singh P., Niederer J.P.M., Versteeg G.F., 2009. Structure and activity relationships for amine-based $\mathrm{CO}_{2}$ absorbents - II. Chem. Eng. Res. Des., 87, 135-144. DOI: 10.1016/j.cherd.2008.07.014.

Tseng P.C., Ho W.S., Savage D.W., 1988. Carbon dioxide absorption into promoted carbonate solutions. AIChE J., 34, 922-931. DOI: 10.1002/aic.690340604.

Vaidya P.D., Kenig E.Y., 2010. Termolecular kinetic model for $\mathrm{CO}_{2}$-alkanolamine reactions: An overview. Chem. Eng. Technol., 33, 1577-1581. DOI: 10.1002/ceat.201000050.

Versteeg G.F., Oyevaar M.H., 1989. The reaction between $\mathrm{CO}_{2}$ and diethanolamine at 298 K. Chem. Eng. Sci., 44, 1264-1268. DOI: 10.1016/0009-2509(89)87026-5.

Yih S.-M., Sun C.-C., 1987. Simultaneous absorption of hydrogen sulphide and carbon dioxide into potassium carbonate solution with or without amine promotors. Chem. Eng. J., 34, 65-72.

Received 15 June 2015

Received in revised form 18 January 2016

Accepted 19 January 2016 


\section{APPENDIX}

- 1. Criterion for pseudo-fist order reaction (Leder, 1971)

$$
\begin{aligned}
& 1+\frac{\left[\mathrm{RR}^{\prime} \mathrm{NH}\right]}{C_{A i}} \gg \sqrt{1+\frac{D_{A} k_{\mathrm{OH}^{-}}\left[\mathrm{OH}^{-}\right]+D_{A} k_{A m}[\mathrm{Am}]}{\mathrm{k}_{\mathrm{L}}^{2}}} \\
& 1+\frac{1}{C_{A i}\left(\frac{1}{a}+\frac{2}{b}\right)} \gg \sqrt{1+\frac{D_{A} k_{\mathrm{OH}^{-}}\left[\mathrm{OH}^{-}\right]+D_{A} k_{A m}[\mathrm{Am}]}{k_{L}^{2}}}
\end{aligned}
$$

Both these criteria (A1) and (A2) must be met.

- 2. Criterion for fast reaction (Pohorecki and Wroński, 1977)

$$
\frac{\sqrt{D_{A} k_{1}}}{k_{L}} \gg 1
$$

